\title{
Kahoot Application in English Language Teaching (ELT) Context: An Alternative Learning Strategy
}

\author{
Nunung Susilo Putri \\ Universitas Lancang Kuning, Pekanbaru, Indonesia \\ nunung@unilak.ac.id
}

\author{
ARTICLE HISTORY \\ Received : 28 April 2019 \\ Revised : 25 May 2019 \\ Accepted : 22 June 2019 \\ KEYWORDS \\ Learning Strategy \\ Kahoot \\ App \\ English Language Teaching (ELT) \\ Teacher
}

\begin{abstract}
This research was designed in descriptive qualitative research. Data were collected from several related works of literature on the application of Kahoot online application in English classrooms. This present study has taken pointers from previous studies that have proven the effectiveness of using video as a learning medium for students, especially in EFL classes. Also, it not only gives students pleasure to learn but also can make students more active and comfortable in the learning process. Besides, the teacher, as a model, must also know how to deliver excellent material using Kahoot online application. Moreover, before using this online application as a medium for teaching, teachers must have a step by step plan of what the teacher must do during teaching and learning. This result has been proven around the globe by many scholars that teaching English using media such as Kahoot is one effective strategy that makes students enjoy the teaching and learning process.
\end{abstract}

\section{Introduction}

The purpose of learning English is to equip students who can communicate with a sufficient level of skill in listening, speaking, reading and writing. According to Balla (2017), teaching English in schools is essential not only academically but also in practical aspects of learning, such as using the language for various purposes including but not limited to business goals, communication, reading foreign literature or other types. There many factors that indicate that English instruction is vital in communication and use throughout the world (Wekke, Yandra, \& Hamuddin, 2017). Muhammad (2018) mentions the function of English as a vehicle for interaction and communication tools. Furthermore, English language teachers and students in schools can implement strategies so that teaching and learning English will be natural and straightforward. Learning as a planner and the process of implementing teaching and learning has a broad understanding that addresses the development of existing science and technology.

The reason for the low quality of education is the inappropriate method of use, the inadequate evaluation tools the material provided is not per the level of thinking of students. The use of appropriate learning media will have a positive impact on the learning process and increase student learning achievement. There is no single group that is considered the best, and there is no single media that is suitable for all types of learning material. Demands for teachers can master a variety of teaching media and can determine which media are suitable for use in learning.
According to Buckingham (2007), media education is an essential dimension of technology in education. It can help bridge the new digital divide between students experiences of technology outside of school and their experiences in the classroom. The study also found focuses on three ways in which using media can respond to new digital media, by applying and extending existing conceptual approaches to the objects of this new study, addressing the creative possibilities of digital technology, and the pedagogical challenges it represents and can explore the potential forms of participatory media culture that emerge. Ahmad (2012) claims that the response of EFL students to media technology can have an impact that can improve accent patterns in individual English words and can improve students writing skills.

Furthermore, English teachers strive to be able to integrate media technology in the ELT class to increase student motivation, integrated language skills and an independent learning environment for students (Sari, Putri, Herdi, \& Hamuddin, 2018). Moreover, Lee (2016) mentions that using it through new media technology students are highly motivated and can express great interest in the media literacy curriculum. Furthermore, students can use laptop, computers and iPads to explore and discuss media problems in the classroom. They can also strengthen their 4C skills (critical thinking, creativity, communication and collaboration). Using new information technology to teach educational media is very useful because the new curriculum can create "meaning" and "relevance" for students. 
Learning media must be adapted to environmental conditions, subject matter, infrastructure and learning objectives. The use of appropriate learning media can be seen from the effectiveness and efficiency of the media in achieving learning objectives. Furthermore, this study will explore the Application of Learning Strategy using Kahoot. In order to improve English learning, many approaches, strategies, media and learning models have been applied. According to Al-Hadithy (2018), Kahoot is an online learning game that can grow students' intrinsic motivation. He revealed that there was a marked increase in active learning, student involvement, self-efficacy, independent learning and an increase in the results of summative assessment after integrating Kahoot.

Medina (2017) considered Kahoot as a tool for vocabulary teaching and learning in English classes. Then in the study also provides further evidence that the use of Kahoot in the learning process can increase student learning motivation and increase student vocabulary. Students' satisfaction shows that EFL learners enjoy using Kahoot in the classroom learning process, and this media is easy to use by students. Furthermore, it was revealed that students generally had a positive view of using Kahoot in the learning process and preferred learning using technology. Budiati (2017) pointed out that the study of Kahoot, designed as a combination of the use of ICT in education and games, is very applicable in English classes to improve student learning. After using Kahoot in the learning process, students are very interested in joining the class, they are more eager to come to class, they are more attentive in the world of English and they are interested in learning more about what they have learned and can convey to others what they have learned using Kahoot in the classroom. Bicen (2018) claims the Kahoot application can be used effectively for the gamification of lessons, giving an impact on students which makes them more ambitious and motivated to learn. Using Kahoot online media in the learning process can enrich the quality of student learning in the classroom, with the highest influences reporting on class dynamics, involvement, motivation and improving learning experiences. Finally, implementing Kahoot shows that the use of educational games in the classroom is likely to minimize disruption, thereby improving the quality of teaching and learning beyond what is provided in conventional classrooms.

\section{Method}

This study was designed as a qualitative descriptive research. The data was collected from several related works of literature on the application of the Kahoot online media in English classrooms. As researchers know, Kahoot online media application is a popular app that is always used by many people in this world. This app is mainly used in assisting the teaching process by teachers or lecturers in the ELT class to help the learning process run efficiently.
The method used in this research is qualitative. Referring to Leavy (2014) and Luttrell (2019), this study understands that words as the qualitative data can be derived from numbers or concepts to reveal detailed descriptions of phenomena. The research subjects were students and also saw responses from students when the teacher provided learning with the help of Kahoot online application. The teachers were involved because they wanted to know how effective the use of Kahoot was in teaching English courses in the ELT class. The steps of data analysis are using observations and interviews of several students. Finally, the researchers made the conclusions based on the results.

\section{Results \& Discussion}

The results of this study after looking at several studies related to using Kahoot online-based applications as a medium of teaching and learning are that Kahoot has many advantages such as free learning platform-based games, as educational technology. By playing Kahoot, this learning becomes very fun and makes students not bored following learning which is very difficult to understand. Using Kahoot aims as a formative assessment for teachers, it can help teachers monitor each student's progress towards learning goals, identify strengths and weaknesses, and to identify areas where students will benefit from more than one teaching, more challenging learning opportunities, or reviews of basic knowledge for the subject. More experienced users also integrate Kahoot into their curriculum to introduce new topics, improve retention of new facts, revise before exams, challenge classes around the world, opinion surveys, gather insights, facilitate discussion, or to reward and restore learners energy in the study.

Besides, the teacher designs learning activities that can make students in active learner mode. In this case, the teachers are challenged to involve students actively during teaching and learning activities using Kahoot. Preparation is one of the main ways to make the use of Kahoot as a powerful tool during teaching and learning activities more meaningful before applying several other ways to encourage students to become active learners.

There are several techniques that can be applied when using media in ELT classrooms, such as Licorish, George, Owen, \& Daniel (2017) stated that higher education institutions have begun to use learning technology, to present lecture content in new ways, to encourage students to participate in classes anonymously and to give them more meaningful revision methods. Teachers and course coordinators integrate into the classroom with the intention of increasing motivation, involvement and students, in turn, learning more deeply. Beyond such interventions, with maturity in learning technology, mobile devices and everywhere are becoming widespread in contemporary classes of settings and are being integrated into many aspects of classroom teaching to encourage Brandford's 
involvement, motivation, and student learning (2013). This confirmation shows that Kahoot, and the use of games and gamification in general, have a positive influence on the dynamics of classrooms, student involvement and motivation, and ultimately, their learning. While our evidence here positively informs pedagogy, and specifically in terms of identifying appropriate contexts that benefit the use of games and gamification, challenges still tend to remain in terms of the time needed to study and regulate this technology, create appropriate content, and provide students with feedback useful and timely feedback. Indeed, time constraints for Kahoot sessions in lectures are reflected in some negative feedback from students, who feel that Kahoot recreational use! Limit the scope of content and waste valuable college time.

Therefore, it is important for the teacher to arrange the lecture carefully, so Kahoot time allocated correctly. Educators are encouraged to balance these challenges in introducing games on an ongoing basis, especially given the potential benefits that can be gained through the use of games during learning sessions. The future research will involve deploying Kahoot on a large scale to check the efficacy of this tool in improving student learning outcomes, using design and explore teacher experiences using Kahoot in improving their teaching effectiveness. Kahoot was used during the pre-test before entering the new material, training, post-test, strengthening material, remedial, enrichment and others, which is sure to be a variation in delivering material so that students stay focused and interested in learning. The equipment that must be prepared in playing Kahoot is the main Laptop, used to open the teachers' questions and controls. Second is the projector, is used to display the question display on the laptop to the screen so that it can be seen by many students. Third students devices can be laptops, smartphones or tablets, used to answer choice questions. Fourth is the internet network. The first step is to go to https://getkahot.com and click Sign in in the menu on the top right. Then we will be directed to the Sign-in page.

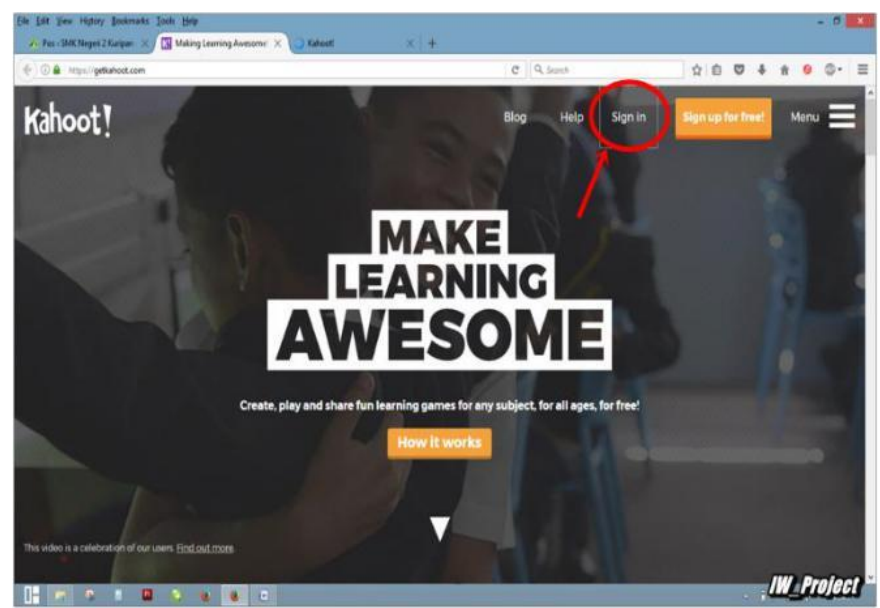

Figure 1. Sign in Page of Kahoot Website
The second step is to enter using the account that was created by entering the email and password. Click on the menu located on the top left. The fourth step is the display of the next page in the list of quizzes that have been made, then select which quiz will be played by clicking the Play button. The fifth step we will be directed to the choice of how to play, namely Classic or Team Mode. Playing the Classic way is chosen if each student has a device to access the Quiz. But if not all students have a device, then it should be made into several groups adjusting to the number of available devices and select the Team Mode menu.

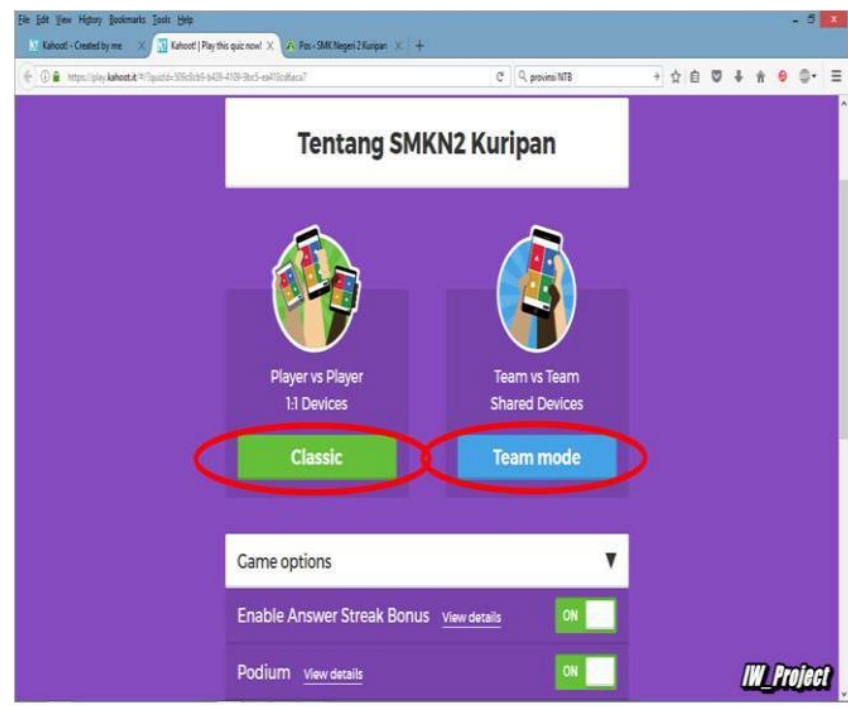

Figure 2. Choosing Between the Classic and Team Mode

If you choose Classic, one student's name will appear. For the Team Mode option, the teacher can enter the names of students in one group. After that, the sixth step is inputting the PIN number that students will use to access Kahoot. Through the device each student is directed to access https://kahoot.it and enter the PIN Number to access this quiz game. We are ready to start playing the quiz with the number of questions that have been taken.

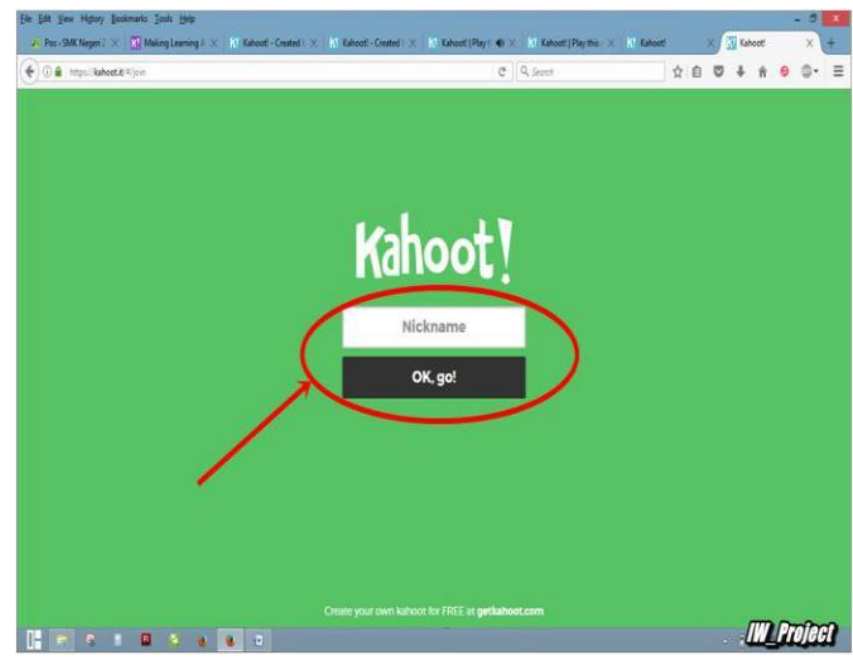

Figure 3. Type the Students' Names 
Display of the teacher's laptop to control the course of the quiz, while on the student's device, only the answer choices will appear. The choice of students' answers will automatically change according to the number question being displayed. Each one of the questions answered by students will immediately appear an analysis of how many students choose each answer choice. This session can also be used to directly discuss the answers to these questions. Discussion of questions can also be done by asking the reason for students who choose the wrong answer. Of course, this will make the discussion interesting, and students will indirectly learn to express their opinions according to their mindset.

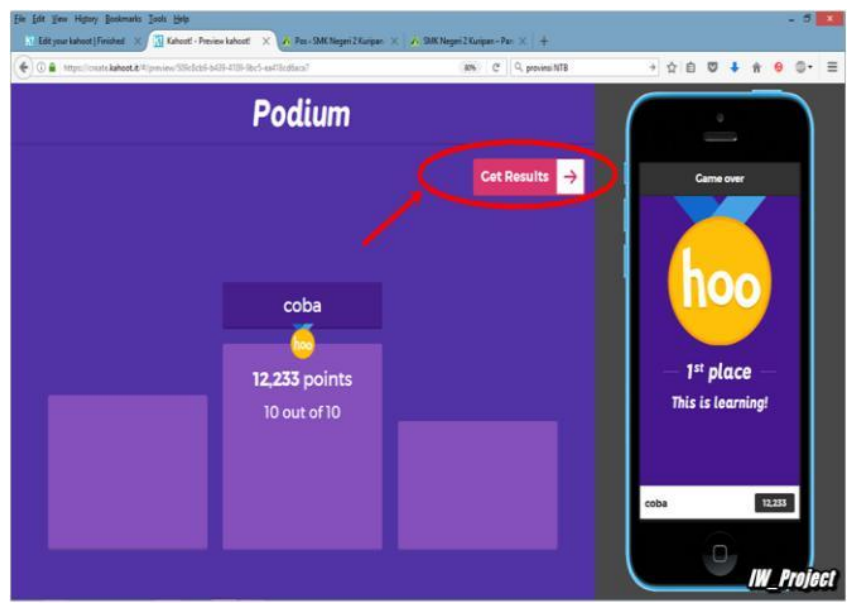

Figure 4. Obtain the Analysis Results

The teacher can also know the extent of the development of the mindset of his students. If it is, then proceed to the question of the next number by selecting the Next button in the upper right corner. The next step before continuing on the question to be addressed will be displayed the temporary value of each student on the question that has been done according to the rank. Repeat the steps until the end of the question. At the end of the session, the names of students with the highest scores will appear. This value is based on the correct score and speed score in answering. For analysis of multiple options, click the Get Result menu.

The next step for analyzing the item about the double choice, please click Save Result, then select Direct Download and click save to my computer. The downloaded file is an excel for the problem item. All the steps we have passed, it's time to apply to students to make learning more interesting, creative and of course, increase student participation.

This finding is related to that can be applied when using media in ELT classrooms, such as Kahoot. Licorish, George, Owen, \& Daniel (2017) stated that higher education institutions have begun to use learning technology, to present lecture content in new ways, to encourage students to participate in classes anonymously and to give them more meaningful revision methods.
Furthermore, the use of Kahoot can help the effectiveness of learning in ELT classroom. Based on the previous research, the use of Kahoot is very effective and helps the learning process in the ELT classroom. According to Bicen (2018), Kahoot application can be used effectively for gamification lessons. By applying gamification using this media can have an impact on students which makes them more ambitious and motivated to learn. Using Kahoot online media in the learning process can enrich the quality of student learning in the classroom, with the highest influences reporting on class dynamics, involvement, motivation and improving learning experiences. In relation to these findings, it has to be committed to them, to be better than before to get an understanding of the material instructions or assignments given by the teacher. So, it can be more effective by using Kahoot in ELT classroom learning.

\section{Conclusion}

The strategy using Kahoot online based application media can increase students learning motivation evidence that the results of learning English can experience a significant increase. With the media, Kahoot can improve student learning achievement as evidence that the results of learning English experience a significant increase in value. It is very helpful for students in addition to understanding English subject matter. Students can also understand ICT delivered by the teacher in the learning process. Based on the results of these studies, there are findings of research related to learning English with Kahoot online based application strategy as an effort to increase student motivation and learning achievement. There are several suggestions that need to be conveyed, namely to implement Kahoot as a learning media that requires proper preparation, so that teachers implement teaching and learning activities are able and truly master the material to be delivered to students.

Then the teachers' role is very important in the continuity of student teaching and learning activities, therefore it is not enough just to teach the material taught, but also the teacher can provide or insert lessons that are character or affective in nature, so as to influence students in increasing motivation. Furthermore, for teachers to always develop their personal cognitive abilities, in order to improve the personal quality of the teacher, so that teaching the teacher easily teaches or implements strategies using Kahoot to support student achievement improvement, especially English subjects and in general other subject matter.

Then, there is a need for continuous follow-up because it can provide knowledge on the extent of good quality and achievement results and can find out the mistakes that need to be addressed. Then, when teaching and learning activities, teachers need to invite a competent teacher to provide meaningful inputs, so that the teacher knows the 
shortcomings that must be addressed in the process of teaching and learning activities.

\section{Acknowledgement}

This research was supported by Applied Linguistic Center at FKIP Universitas Lancang Kuning, Pekanbaru. Indonesia. Therefore, the authors would like to express their sincere gratitude. Any opinions, findings, and conclusions or recommendations expressed in this material are those of the authors and do not necessarily reflect the views of the respected institution.

\section{References}

Ahmad, J. (2012). English language teaching (ELT) and integration of media technology. Procedia-Social and Behavioral Sciences, 47, 924-929.

Al-Hadithy, T., \& Ali, S. (2018). Gamification in learning English for academic purposes: Designing assessment for language using Kahoot with UAE undergraduate law students. In Proceedings of 110th IASTEM International Conference, Toronto, Canada.

Balla, E. (2017). English Language and its Importance of Learning it in Albanian Schools. Academic Journal of Interdisciplinary Studies, 6(s2), 109-114.

Bicen, H., \& Kocakoyun, S. (2018). Perceptions of students for gamification approach: Kahoot as a case study. International Journal of Emerging Technologies in Learning (iJET), 13(02), 72-93.

Buckingham, D. (2007). Media education goes digital: an introduction. Learning, Media and technology, 32(2), 111-119.

Budiati, B. (2017, June). ICT (Information and Communication Technology) Use: Kahoot Program for English Students' Learning Booster. In Proceedings Education and Language International Conference (Vol. 1, No. 1).

Leavy, P. (2014). The Oxford handbook of qualitative research. Oxford University Press, USA.

Lee, A. Y. (2016). Media education in the School 2.0 era: Teaching media literacy through laptop computers and iPads. Global Media and China, 1(4), 435-449.

Licorish, S. A., George, J. L., Owen, H. E., \& Daniel, B. (2017). Go Kahoot!” enriching classroom engagement, motivation and learning experience with games. In Proceedings of the 25th international conference on computers in education (pp. 755-764).

Luttrell, W. (2019). Reflexive Qualitative Research. In Oxford Research Encyclopedia of Education.

Medina, E. G. L., \& Hurtado, C. P. R. (2017). Kahoot! A digital tool for learning vocabulary in a language classroom. Revista Publicando, 4(12 (1)), 441-449.
Muhammad, H. A., Ya'u, S., Aliyu, U. I., \& Hassan, M. (2018). Teaching and learning English language in Nigerian schools: Importance and challenges. Teacher Education and Curriculum Studies, 3(1), 10-13.

Sari, R., Putri, S. E., Herdi, H., \& Hamuddin, B. (2018). Bridging critical discourse analysis in media discourse studies. Indonesian EFL Journal, 4(2), 8089.

Wekke, I. S., Yandra, A., \& Hamuddin, B. (2017, December). Learning Strategy in Class Management: A Reflection from Manado Case. In IOP Conference Series: Earth and Environmental Science (Vol. 97, No. 1, p. 012053). IOP Publishing. 